Canadian Journal of Fisheries and Aquatic Sciences

Canadian

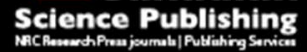

Journal canadien des sciences halieutiques et aquatiques

\title{
Tributary Effects in Rivers: Interactions of Spatial Scale, Network Structure, and Landscape Characteristics
}

\begin{tabular}{|r|l|}
\hline Journal: & Canadian Journal of Fisheries and Aquatic Sciences \\
\hline Manuscript ID & cjfas-2015-0493.R3 \\
\hline Danuscript Type: & Article \\
\hline Complete List of Authors: & $\begin{array}{l}\text { Jones, Nicholas; Ontario Ministry of Natural Resources and Forestry, } \\
\text { Aquatic Research and Monitoring Section } \\
\text { Schmidt, Bastian; Ontario Ministry of Natural Resources and Forestry, } \\
\text { Aquatic Research and Monitoring Section }\end{array}$ \\
\hline Keyword: & continuum, discontinuum, classification, network heterogeneity, NCH \\
\hline \multicolumn{2}{|c}{} \\
\hline
\end{tabular}




\section{Tributary Effects in Rivers: Interactions of Spatial Scale, Network Structure,}

\section{2 and Landscape Characteristics}

3

4

5 Nicholas E. Jones*

6

7

8 755-1559

Bastian J. Schmidt 705-755-1559
River and Stream Ecology Lab, Aquatic Research and Monitoring Section, Ontario Ministry of Natural Resources and Forestry, Trent University, DNA Building 2140 East Bank Drive, Peterborough, ON K9J 7B8 nicholas.jones@ontario.ca Telephone: 1-705-755-2268; Fax: 1-705-

River and Stream Ecology Lab, Aquatic Research and Monitoring Section, Ontario Ministry of Natural Resources and Forestry, Trent University, DNA Building 2140 East Bank Drive, Peterborough, ON K9J 7B8 bastian.schmidt@ontario.ca Telephone: 1-705-755-1581; Fax: 1-

* Corresponding author

Keywords: continuum, discontinuum, classification, network heterogeneity, $\mathrm{NCH}$ 
28 Abstract

29 Landscape characteristics in combination with the physical structure of branched stream

30 networks define the environmental conditions available for lotic biota. From simple stream

31 network "laws" can emerge a spatially explicit understanding of habitat heterogeneity. Based on

32 geographic information system analyses, we explore how stream networks integrate spatial

33 heterogeneity of the landscape and form new characteristics as stream segments accumulate into

34 progressively larger drainages, and how these changes in landscape characteristics relate to

35 confluence symmetry ratio and drainage size. Simple expectations for stream networks include:

36 (i) abrupt changes in longitudinal patterns are more probable among the numerous small and

37 diverse headwater streams than in large, rare, and characteristically similar tributaries, (ii) the

38 many small tributaries flowing into large main stem channels cause individually small, yet

39 collectively gradual changes in longitudinal patterns. Such a spatial understanding of where

40 change is likely to occur helps to reconcile gradual river continuum and abrupt discontinuum

41 views of patterns in rivers and predict the locations of significant confluences, ecological

42 transitions, longitudinal gradients, and patterns of biodiversity in stream networks. 


\section{Introduction}

Within a stream and its valley there are changes in physical and chemical properties from small headwater streams to large lowland rivers (e.g., flow volume, degree of shading, sediment size, organic matter). The River Continuum Concept (RCC; Vannote et al. 1980) describes a continuous gradual gradient in geomorphological changes and corresponding adjustments of organic matter and biota over long distances. Ward and Stanford (1983) proposed the Serial Discontinuity Concept (SDC) recognizing that most rivers experienced abrupt breaks or discontinuities in the continuum from impoundments. Others noted the potential influence of tributaries on a continuous gradient (Bruns et al. 1984). Years later, Fisher (1997) challenged fellow scientists to think of streams in terms of branching systems, or using today's terminology, networks. Since then, the growth of computing power and remote sensing technology has enabled network analysis to rapidly become a topic of much discussion and shifted the paradigm in stream ecology. The linear view of the RCC and SDC has led to the understanding of tributary influences (e.g., Rice et al., 2001) lakes (Jones 2010), and major geological changes (Neff and Jackson 2012) that incorporate network thinking (Poole, 2002; Benda et al., 2004a). Within stream networks each confluence, wetland, lake or impoundment has the potential to punctuate the continuum, resulting in abrupt changes in downstream characteristics (Poole 2002; Jones 2010). This hierarchical patch dynamics view emphasizes variation in pattern, which can reset longitudinal trends forward or backward along the stream (Poole 2002).

Research on the influence of tributaries has largely focused on localized small-scale $\left(10^{1}\right.$ $10^{3} \mathrm{~m}$ ) changes in main stem river characteristics at the point where tributaries join main stem rivers (Bruns et al. 1984; Perry and Schaeffer 1987; Kiffney et al. 2006; Milesi and Melo 2014; Hellmann et al. 2015). Much of this research has focused on geomorphological changes in an 
72 effort to identify significant tributaries (e.g., Rice 1998; Benda et al. 2004b). Intuitively, the

73 probability of "significant" confluence effect is a function of tributary size relative to the main

74 stem river (confluence symmetry ratio, CSR, Rice 1998; Benda et al. 2004a). Larger tributaries,

75 relative to main stem size, are more likely to show significant confluence effects compared to

76 relatively small tributaries (Rhoads 1987; Rice 1998). Local geomorphic effects include abrupt

77 changes in sediment quantity and size distribution, wood debris, and flow-related changes

78 including channel width, water depth and velocity. In mountainous streams, local confluence

79 effects can be pronounced (e.g., western USA, sediment rich and high energy systems; see Rice

80 et al. 2001; Benda et al. 2004a,b), whereas, in many other stream types around the world

81 tributaries show little geomorphic influence at confluences. Instead, biophysical characteristics

82 of drainages such as land use, vegetation, and geology drive changes in water quantity quality,

83 and thermal regimes that shape the abiotic and biotic characteristics of rivers (Hynes 1975, Rice

84 et al. 2001, Benda et al. 2004).

There has been little effort to understand how tributaries influence abiotic and biotic characteristics further downstream from confluences and across entire drainages, beyond the

87 mixing zone (Gaudet and Roy 1995) and the immediate geomorphic influence of the tributary

88 (but see Stevens et al. 1997; Rice et al. 2001; Benda et al. 2004a; Torgersen et al. 2008). Aside

89 from sudden fine-scale changes in physical and biological characteristics at confluence "hot

90 spots" (sensu Benda et al. 2004a), tributary streams can have persistent and far reaching

91 downstream impacts on water quality, thermal and flow regimes, and biotic communities,

92 imparting change many kilometers downstream (Rice et al.2001; Benda et al. 2004a). This type

93 of understanding is required to identify breaks in networks that aid in the classification of

94 ecologically meaningful homogeneous stream segments $\left(10^{2}-10^{5} \mathrm{~m}\right.$ in length) for use in 
95

96

97

98

99

100

101

102

103

104

105

106

107

108

109

110

111

112

113

114

115

116

monitoring programs (Seelbach et a. 2006; Brenden, et al. 2008; Melles et al. 2014) and species distribution modelling (Zorn et al. 2011; McKenna et al. 2014). Such classifications use remotely sensed or thematically mapped information (e.g., surficial geology) in combination with stream network information (e.g. upstream drainage area) to make inferences about the ecological character of streams, particularly over large areas (e.g., states and provinces) where every stream reach cannot be visited in the field to gather fine-scale data. The premise of stream segmentation is to delineate spatial units using statistical methods where environmental variation within the resulting segments is less than the environmental variation between segments (Bizzi and Lerner 2012; Wang et al. 2012; Alber and Piégay 2011). In a hierarchical framework this generalizes finer scale variability within segments such as sedimentary links, pools, rifles, and lateral sediment sources to answer questions at appropriate scales (Frissell et al. 1986; Rice and Church 1998). Recently, stream network segmentation schemas have been tested to assess the homogeneity within segments and whether assigned classes are actually different (Warrner et al. 2010). For these types of assessments, researchers avoid sampling near confluences because they are not representative of stream reaches and segments as a whole because of complex fluvial dynamics and flow mixing.

Streams are an integration of the landscape they drain which ultimately defines habitat for aquatic biota in streams (Hynes 1975; Zorn et al. 2002; Allan 2004). Landscape characteristics in combination with the physical structure of branched stream networks define the environmental conditions and habitat heterogeneity available for lotic biota and relates to patterns of ecological diversity (Finn et al. 2011). From simple stream networks "laws" can emerge an understanding of habitat heterogeneity. These laws include: 
117 1. "The valley rules the stream" emphasizing the importance that geology and vegetation has on a stream's flow, temperature, and availability of ions and organic matter that form the basis of the nutrient cycle for the biota (Hynes 1975). During the last two decades, numerous multi-scale studies in streams have shown the importance of landscape conditions and scale in driving fish and invertebrate communities (Richards et al. 1996; Allan and Johnson 1997; Hughes et al. 2006). Differences in landscape characteristics lead to differences in stream typology.

2. Large tributaries, relative to the main stem, will have a large confluence symmetry ratio (CSR) and are more likely to cause abrupt changes in abiotic and biotic characteristics than small tributaries. In contrast to other studies (e.g., Benda et al. 2004a) that focus on effects immediately at a confluence we are interested in the effects that persist downstream at the segment scale. For example, a large tributary will add significantly more flow than a small one, which changes stream hydraulics and stream width, which opens the riparian canopy and reduces shading, likely causing abrupt and persistent changes in thermal regime and for the purposes of typology creates a new class of stream segment.

3. In every stream network there are many more headwater streams than larger higher order streams and this relationship is approximated by a geometric progression according to the law of stream numbers (Horton 1945). For instance, headwater streams $\left(<10 \mathrm{~km}^{2}\right)$ account for 60 percent of stream channel length in the United States (Wang et al. 2011).

4. Smaller streams also drain smaller areas than large streams (Schumm 1956) and, in turn, their characteristics can be very homogeneous because their drainage encompasses only a single type of landscape (e.g., 100\% forested or 100\% sandy till) which is in contrast to 

large rivers that usually integrate from a heterogeneous landscape composed of many types (Wiens 1989; Fig.1).

We hypothesize that the probability of a persistent abrupt change downstream from a confluence is a function of both CSR and the similarity of drainage landscape characteristics in a logistic functional form (Equation 1; Fig. 2), where $p$ is the probability of an abrupt change downstream of a confluence and is a function of the landscape dissimilarity $a=\{10,20$, $30 \ldots 100\}$, the constant $b=14$, and the confluence symmetry ratio $c=\{0.1,0.2,0.3 \ldots 1.0\}$.

$$
p=\frac{1}{1+e^{-(a+b c)}}
$$

Figure 2 represents a reasonable hypothesis. We chose the logistic form for its probabilistic interpretation because we expected the probability of a detectable change to happen abruptly. Estimates of threshold values and true functional form need to be determined in future research. In this hypothesis the probability of a significant change in the ecology downstream form a tributary is high when two streams merge of a similar size (CSR $>0.8)$ and have similar landscape characteristics (Euclidean distance $<10$ ). As the similarity of the two drainages decreases, the inflection point of the logistic function shifts to progressively smaller CSR values (Fig. 2). This recognizes that a small tributary might influence downstream characteristics on the main stem if it is very different in character (i.e., draining a very different landscape). For example, a relatively small, warm and turbid tributary flowing into a cold clear trout stream may cause greater changes in the main stem then a similarly sized tributary that is also cold and clear. These relationships in concert setup simple expectations for the relative importance of confluences in stream networks and provide a physical basis for the likelihood of change downstream of tributaries and network heterogeneity of habitats. 
Based on geographic information system (GIS) analyses across southern Ontario, we

163

164

165

166

167

168

169

170

171

172

173 174 Composition Hypothesis ( $\mathrm{NCH})$.

explore how stream networks integrate spatial heterogeneity of the landscape and form new characteristics as stream segments combine into progressively larger drainages, and how these changes in landscape characteristics relate to confluence symmetry ratio and drainage size. From these analyses we make inferences about how environmental gradients within stream networks may unfold and structure riverine habitats. We emphasize cumulative downstream impacts as a function of scale-dependent landscape heterogeneity that explicitly attempts to recognize the role of tributaries that is broader than aggradation-driven geomorphological impacts. We advance on previous research and provide direction on the likelihood of abrupt and gradual change within stream networks. Such an understanding is useful for the development of system rules and the discretization of stream networks into ecologically meaningful stream classes. Lastly, in the tradition of other concepts and hypotheses in stream ecology we call this the Network

175 Methods

$177(\mathrm{n}=21,473)$ and confluence points $(\mathrm{n}=10,705)$ in southern Ontario (land area $\left.136,907 \mathrm{~km}^{2}\right)$

178 Southern Ontario is represented by a complex physiography with a mixture of geologies, glacial

179 histories and landforms e.g. escarpments, end moraines, glacial lake plains, and drumlins. It also 180 has a mosaic of land covers including wetlands, agriculture, fragmented forest, and urban areas.

182 drainage areas were summarized for each reach creating area-weighted average values for base

183 flow index (BFI, Neff et al. 2005; Piggott and Sharpe 2007), percentage of total area wetland, 
184 forested, agriculture, and clay geology. These landscape variables were chosen to illustrate the 185 effect of averaging at different spatial scales using variables of interest to aquatic ecologists.

186 Many other landscape variables could have been chosen to illustrate the averaging effect. Base

187 flow index represents the long-term average rate of base flow relative to the long-term average 188 rate of total stream flow in five classes of quaternary geology including coarse and fine textured 189 sediments, till, shallow bedrock and organic deposits (Piggott and Sharpe 2007). The base flow 190 index is a useful surrogate for actual groundwater delivered to a stream, and therefore, important 191 in stream hydrology and thermal regime characteristics both of which are very important in 192 defining stream habitat.

We assigned a confluence symmetry ratio and similarity value to each confluence in southern Ontario to illustrate that small main stem streams have a wide range of confluence 195 symmetry ratios and landscape similarities and that progressively larger main stem streams have mostly small CSRs. Using the variables described above, similarity in landscape characteristics

197 between the main stem and tributary drainages was calculated using Euclidean distance $(E D)$.

198 Other variables could be chosen depending on objectives and region. For the matrix in Figure 2 199 all Euclidean distance measures were transformed as landscape similarity $=(E D / 10)-11$. This 200 created drainages and confluence points for which we plot relationships between drainage 201 characteristics in relation to drainage size of the main stem (area $\mathrm{km}^{2}$ ) and similarity of 202 landscape characteristics.

We also examined more specific patterns in individual drainages to show interrelationships among CSR, the similarity of drainage characteristics, and the probability of an

205 abrupt change. Focusing on the main stem and five of the largest tributaries of the diverse

206 Saugeen River (N 44.50 , W $81.37^{\circ}$, drainage area 3,983 $\mathrm{km}^{2}$ ), we applied the network 
207 composition hypothesis described in Figure 2 to confluences and plot the expected pattern of

208 continuous and abrupt changes in longitudinal pattern on the main stem and the major tributaries.

209 We also plotted all confluences in the Saugeen drainage with the potential for change by

210 drainage area. Due to binning of the continuous values in Figure 2, the first column $(\mathrm{CRS}<0.1)$

211 contains many $(n=4189)$ very small CSRs $($ mean $=0.03)$ with very low probability of causing an

212 abrupt change downstream of a confluence.

213 Results

Among Drainages in Southern Ontario

Small headwater streams are more variable in landscape characteristics and more

217 approach the mean value $(\mathrm{BFI}=46 \%)$ of the entire data set (Fig. 3). Strong decreases in the

218 diversity of BFI values starts at approximately $40-100 \mathrm{~km}^{2}$ and asymptotes around the mean at

219 approximately $4,000 \mathrm{~km}^{2}$. Similar patterns were found for the other variables percentage

220 wetland, forested, agriculture, and clay geology.

In headwater streams $\left(<10 \mathrm{~km}^{2}\right)$ there were many confluences that spanned the full range

222 of confluence symmetry ratios. Headwater streams also spanned a wide range of similarities in

223 landscape characteristics; although there were more headwater streams that were similar than

224 very different (Fig. 4). As drainages grow in size, the number tributaries that are similar in size

225 to their main channel decrease. Differences in landscape characteristics between tributaries and

226 the main stem also decrease, particularly for large CSR values.

227 The number and frequency of confluences characterised by CSR and landscape similarity

228 in drainage networks shows a pattern (Fig. 5). There are many relatively small tributaries with 
229 similar drainage characteristics (top left). Large tributaries that have contrasting landscape

230 characteristics are very rare (bottom right). Using $>0.9$ probability of a significant confluence

231 from Fig. 2 we calculate that there are 1,400 significant confluences causing segment breaks of a

232 possible 10,705 in southern Ontario. That is, $13 \%$ of the confluences are likely to show

233 significant physical, chemical and biological effects in the stream segments downstream of the

234 confluences, assuming the underlying principles of this analysis hold true.

\section{Within Drainages- Saugeen River}

The Saugeen River has six main tributaries including the main stem. Based on the NCH,

237 we expected a pattern of abrupt changes tending to occur more frequently within headwater areas

238 where there are many small streams and a higher potential for large differences in landscape

239 characteristics (Fig. 6 and 7). This pattern was particularly evident on the larger branches of the

240 Saugeen (e.g., main stem and South Saugeen). Although there were a couple of exceptions in

241 mid-reaches, a more gradual gradient was apparent in larger drainage areas further downstream

242 (Fig. 6 and 7). The North Saugeen River has an elongated drainage shape and few confluences

243 with large CSRs where changes could occur, that is, few of its tributaries are large enough.

244 Across the entire Saugeen River drainage there were 1,470 confluences, $193(13 \%)$ had a

245 probability $(>0.9)$ of being a significant confluence, $267(18 \%)$ were between 0.1 and 0.95 , and

$2461,010(69 \%)$ confluences had a potential for change $<0.1$ (Fig. 8).

\section{Discussion}

The averaging of landscape characteristics in progressively larger drainages means that

249 larger drainages will tend to have similar landscape and environmental characteristics, and thus, 250 ecology (Wiens 1989). This similarity is predicated on the idea that the valley rules the stream 
251 (Hynes 1975). Plots of drainage size (area) in relation to drainage characteristics for most 252 variables will show a trumpet-shaped distribution of data points with high diversity for small 253 drainages and low diversity for larger drainages. Similar trumpet shaped distributions can be 254 found in the relationship between low-flow yield and catchment area in Zorn et al. (2011, Fig 255 2a). This is a simple mathematical determination. As drainage size increases, a greater proportion 256 of the spatial heterogeneity is contained and averaged. This relationship will not hold true for 257 landscape variables that have little variation over regional or drainage scales (e.g. air 258 temperature). Our analysis occurred in a very patchy, post-glacial landscape. In more 259 homogenous landscapes, where the size of the landscape patches matches or exceeds the size of 260 even the largest drainages, confluence symmetry ratio might be the main driver of change. Aside from being relatively average in characteristics, larger rivers are also rarer on the

262 landscape based on the law of stream numbers (Horton 1945). In turn, this means that finding a 263 confluence of two large rivers with very different landscape characteristics is even rarer. Hence, 264 abrupt changes in longitudinal pattern are more likely to involve confluences of smaller streams. 265 There are, however, great examples of large contrasting rivers joining. For example, the 266 confluence of the turbid Fraser and clear Thompson Rivers at Lytton, British Columbia, or the 267 Colorado and the slightly smaller and silty Green Rivers in Utah, or the turbid Mamoré River 268 and the clear Itenez River in Bolivia or the confluence of the Rhone and muddy Arve Rivers in 269 Switzerland. Many of these large river confluences have contrasting turbidity and cross over 270 major geological/ecological boundaries. We should expect stream segments downstream of 271 significant confluences such as these to have characteristics (e.g., physiochemical, biological) 272 different than adjacent upstream segments of the tributary and the main stem. 
We anticipate that it is more common for small streams to merge with contrasting

274 environmental and ecological characteristics such as thermal, sediment, or flow regimes, to

275 become something entirely different supporting different fishes and invertebrates downstream of

276 the confluence. Headwater streams are numerous and because of their small drainages, can be

277 very specific to certain landscape conditions (e.g., geology type, land cover) and as a result even

278 directly neighbouring streams can be different from each other. Such variation and juxtaposition

279 in environmental characteristics is common in headwaters and is likely to cause ecological

280 changes downstream of confluences in these areas and influence biological diversity (Finn et al.

$2812011)$.

In contrast, along large main stem rivers hundreds of small tributaries with small confluence symmetries may join without causing noticeable changes individually despite most

284 likely being different from the large main stem that exhibits the average conditions of the 285 drainage. Thus, the distance between significant confluences or different stream typologies 286 becomes greater as rivers increase in size (Benda et al. 2004a,b). At the same time, small 287 incremental changes in flow volume and environmental characteristics lead to continuous 288 gradual changes in pattern and process. Such information is vital to researchers attempting to 289 classify stream valley segments, particularly on large main stem valley segments. In many cases, 290 there will not be a tributary large enough to cause significant changes in stream typology for 291 many kilometers yet the river may have significantly increased in size (e.g., double bankfull 292 width) since the last significant confluence upstream. Measures other than landscape 293 characteristics described above need to be used to elicit a break in the stream segment (e.g., 294 sudden changes in geology, waterfalls, drainage area). Such a spatial understanding of where 
295 change is likely to occur within drainages helps to reconcile river continuum (gradual) and 296 discontinuum (abrupt) views of patterns in rivers.

297 Basin shape has important implications for longitudinal patterns (Benda et al. 2004a, Rice 298 2016). Round-shaped drainages have more large tributaries likely capable of causing change 299 compared to elongated drainages. The Saugeen River is a good example of a round drainage 300 where significant changes do occur in the mid-reaches at major tributary confluences. Elongated 301 drainages with narrow valleys, as noted on the North Saugeen River sub-watershed, have many 302 small tributaries that by themselves cannot cause abrupt changes yet flows still accumulate 303 leading to gradual change.

Streams are an integration of the landscape which ultimately define habitat for biota.

305 Contrasting stream types merging at confluences have the potential to create ecotones and these 306 heterogeneous junctures are often hot spots for local scale $\alpha$ biodiversity (Osborne and Wiley 307 1992; Kiffney et al. 2006; Milesi et al. 2014; Hellmann et al. 2015). Increasing to the basin scale, 308 Finn et al. (2011) documented that among site $\beta$ biodiversity of benthic invertebrates was much 309 greater among headwater than in mid-order streams at both population-genetic and community 310 levels. Small headwater streams contributed significantly to basin-scale biodiversity through 311 high levels of among-site habitat variation across stream networks (Finn et al. 2011). We 312 similarly found that headwater streams are diverse in characteristics because they often drain 313 specific types of landscape, not the average condition of a larger area (Wiens 1989). The 314 extremes associated with headwater streams have led to difficulties in modelling. Seelbach et al. 315 (2011) noted how regression models predict the central tendency of data well but often fail in 316 predicting extremes. They further note that small catchments are very abundant within river 317 networks and suffer prediction errors as they often have homogeneous landscape characteristics 
318 319 320

321

323

324 325 326 327 328 329 330

and are not well-represented by gaged data from long-term monitoring sites (Seelbach et al. 2011).

The NCH provides a physical basis for the likelihood of change in the characteristics of stream segments downstream of tributaries and patterns of heterogeneity of habitats across entire drainage networks. Through the inputs of water, sediment, and organic material, each tributary contributes to incremental change within a stream network: many are small changes and a few are large changes. Using simple confluence symmetry ratios and landscape similarity measures, other researchers can generate maps and an understanding of where to expect changes within stream networks. Our approach is not limited to mountain streams and their geomorphically significant confluences but is applicable to all stream types. Such spatially explicit hypotheses can be tested and help guide field sampling campaigns. Synthetic models and field research are required to determine which combinations of CSR and landscape similarity produce significant changes in abiotic conditions and the ecology for stream segments that are meaningful to management. Given the small magnitude of change expected at many confluences, ecological thresholds might be difficult to detect and determine what is significant given the natural spatial and temporal variability of streams and the resolution and extent of traditional sampling methods (Torgersen et al. 2008). Detection will likely be more successful by measuring physical variables such as small changes in discharge, water quality, and temperature than biological measures e.g., benthic invertebrate communities (but see Rice et al. 2001). Geographic information systems, remote sensing, innovative statistical and field methodological approaches and technologies, and new views such as network thinking will provide opportunities to develop testable hypotheses about ecological patterns and processes that will help protect and conserve flowing waters. 


\section{Acknowledgements}

342 We appreciate the helpful reviews from Paul Seelbach and Stephen Rice.

343 References

344 Alber, A., and Piégay, H. 2011. Spatial disaggregation and aggregation procedures for 345 characterizing fluvial features at the network-scale: Application to the Rhône basin 346 (France). Geomorph. 125: 343-360.

347 Allan, J.D. 2004. Landscape and riverscapes: The influence of land use on river ecosystems.

348 Annu. Rev. Ecol. Evol. S. 35: 257-284

349 Allan, J.D., and Johnson, L.B. 1997. Catchment-scale analysis of aquatic ecosystems.

$350 \quad$ Freshwater Bio. 37:107-111.

351 Benda, L., Poff, N.L., Miller D., Dunne, T., Reeves, G., Pess, G., and Pollock, M. 2004a. The 352 network dynamics hypothesis: How channel networks structure riverine habitats.

353 BioScience 54: 413-427.

354 Benda, L, Andras, K, Miller D., Bigelow, P. 2004b. Confluence effects in rivers: Interactions of 355 356 basin scale, network geometry, and disturbance regimes. Water Resour. Res. 40: W05402, doi:10.1029/2003WR002583.

357 Bizzi, S., and Lerner D.N. 2012. Characterizing physical habitats in rivers using map-derived drivers of fluvial geomorphic processes. Geomorphology 169-170: 64-73. 
359 360

361

362 363

364

365

366

367

368

369

370

371

372

Brenden, T.O., Wang, L. and Seelbach, P.W. 2008. A river valley segment classification of Michigan rivers and streams based on fish and physical attributes. Trans. Amer. Fish. Soc. 137: 1621-1636.

Bruns, D.A., Minshall, G.W., Cushing, C.E., Cummins, K.W., Brock, J.T., and Vannote, R.C. 1984. Tributaries as modifiers of the river continuum concept: Analysis by polar ordination and regression models. Arch. Hydrobiol. 99: 208-220.

Finn, D.S., Bonada, N., Múrria, C., and Hughes, J.M. 2011. Small but mighty: headwaters are vital to stream network biodiversity at two levels of organization. J. N Amer. Bentho. Soc. 30: 963-980.

Fisher, S.G.1997. Creativity, idea generation and the functional morphology of streams. J. N Amer. Bentho. Soc. 16:305-318.

Frissell, C.A., Liss, W.J., Warren, C.E., and Hurley, M.D. 1986. A hierarchical framework for stream habitat classification: viewing streams in a watershed context. Environ. Manag. 10: $199-214$.

Gaudet, J.M. and Roy, G.A. 1995. Effect of bed morphology on flow mixing length at river confluences. Nature 373: 138-139.

Hellmann, J.K., Erikson, J.S., Queenborough, S.A. 2015. Evaluating macroinvertebrate community shifts in the confluence of freestone and limestone streams. J. Limno. 74: 6474.

Horton, R.E. 1945. Erosional development of streams and their drainage basin: Hydrophysical approach to quantitative morphology, Geol. Soc. Am. Bull., 56: pp275-370. 
380

381

382

383

384

385

386

387

388

389

390

391

392

393

394

395

396

397

398

399

Hughes, R., Wang, L., and Seelbach, P.W. Editors. 2006. Landscape influences on stream habitats and biological communities. American Fisheries Society, Symposium 48.

Hynes, H.B.N. 1975. The stream and its valley. Verhandlungen der Internationalen Vereinigung fur Theoretischeund Angewandte Limnologie 19:1-15.

Jones, N.E. 2010. Incorporating Lakes within the River Discontinuum: Longitudinal Changes in Ecological Characteristics in Stream-Lake Networks. Can. J. Fish. Aquat. Sci. 67: 13501362.

Kiffney, P.M., Greene, C.M., Hall, J.E., and Davies, J.R. 2006. Tributary streams create spatial discontinuities in habitat, biological productivity, and diversity in mainstem rivers. Can. J. Fish. Aquat. Sci. 63:2518-2530.

McKenna, J.E. Jr., Schaeffer, J.S., Stewart, J.S. and Slattery, M.T. 2014. Development of a spatially universal framework for classifying stream assemblages with application to conservation planning for Great Lakes lotic fish communities. Restor. Eco., 23: 167-178. DOI: $10.1111 /$ rec. 12146

Melles, S.J., Jones, N.E., Schmidt, B.J. 2014. Evaluation of Current Approaches to Stream Classification and a Heuristic Guide to Developing Classifications of Integrated Aquatic Networks. Environ. Manage., 53: 549-566. DOI 10.1007/s00267-014-0231-0

Milesi, S.V., and Melo, AS. 2014. Conditional effects of aquatic insects of small tributaries on mainstream assemblages: position within drainage network matters. Can. J. Fish. Aquat. Sci. 71:1-9. 
400 Neff, B.P., Day, S.M., Piggott, A.R. and Fuller, L.M. 2005. Base flow in the Great Lakes Basin. 401 U.S. Geological Survey Scientific Investigations Report 2005-5217, Washington, D.C., $402 \quad$ USA.

403

404

405

406

407

408

409

410

411

412

413

414

415

416

417

418

419

Neff, M.R., and Jackson, D.A. 2012. Geology as a structuring mechanism of stream fish communities. Trans. Amer. Fish. Soc. 141:962-974.

Osborne, L.L., and Wiley, M.J. 1992. Influence of tributary spatial position on the structure of warmwater fish communities. Can. J. Fish. Aquat. Sci. 49: 671-681.

Piggott, A.R. and Sharpe, D.R. 2007. Geological interpretations of baseflow for southern Ontario p. 394-401. In Proceedings of the 60th Canadian Geotechnical and 8th Joint IAH-CNC and CGS Groundwater Specialty Conferences. Canadian Geotechnical Society and Canadian National Chapter of the International Association of Hydrogeologists.

Poole, G.C. 2002. Fluvial landscape ecology: addressing uniqueness within the river discontinuum. Freshw. Biol. 47: 641-660.

Rice, S.P. 1998. Which tributaries disrupt downstream fining along gravel-bed rivers? Geomorphology 22: 39-56.

Rice, S.P. 2016. Tributary connectivity, confluence aggradation, and network biodiversity. Geomorphology DOI: 10.1016/j.geomorph.2016.03.027

Rice, S.P., Greenwood, M.T., and Joyce, C.B. 2001. Tributaries, sediment sources, and the longitudinal organisation of macroinvertebrate fauna along river systems. Can. J. Fish. Aquat. Sci. 58: 824-840. 
420

421

422

423

424

425

426

427

428

429

430

431

432

433

434

435

436

437

438

439

Richards, C., Johnson, L.B. and Host, G.E. 1996. Landscape-scale influences on stream habitats and biota. Can. J. Fish. Aquat. Sci. 53: 295-311.

Rhoads, B.L. 1987. Changes in stream characteristics at tributary junctions. Phys Geogr 8: 346361.

Schumm, S.A. 1956. Evolution of drainage systems and slopes in badlands at Perth Amboy, New Jersey. Geol. Soc. Amer., 67: 597-646.

Seelbach, P.W., Wiley M.J., Baker M.E., Wehrly K.E. 2006. Initial classification of river valley segments across Michigan’s lower peninsula. American Fisheries Society Symposium 48: $25-48$.

Seelbach, P. W., Hinz, L.C., Wiley, M.J., and Cooper, A.R. 2011. Use of multiple linear regression to estimate flow regimes for all rivers across Illinois, Michigan, and Wisconsin. Michigan Department of Natural Resources, Fisheries Research Report 2095, Lansing.

Stevens, L.E., Shannon, J.P., and Blinn, D.W. 1997. Colorado River benthic ecology in Grand Canyon, Arizona, USA: Dam, tributary and geomorphological influences. Reg. Riv. Res. Manag. 13: 129-149.

Torgersen, C.E., Gresswell, R.E., Bateman, D.S., and Burnett, K.M. 2008. Spatial identification of tributary impacts in river networks In River Confluences, Tributaries and the Fluvial Network Edited by S. Rice, A. Roy, B. Rhoads. West Sussex, UK, John Wiley \& Sons Ltd., p. 159-181. 
440 441

442

443

444

445

446

447

448

449

450

451

452

453

454

455

456

457

458

459

460

Vannote, R.L., Minshall G.W., Cummins K.W., Sedell J.R., and Cushing C.E. 1980. The river continuum concept. Can. J. Fish. Aquat. Sci. 37: 130-137.

Wang, L., Infante, D., Esselman, P., Cooper, A., Wu, D., Taylor, W., Beard, D., Whelan, G., and Ostroff, A. 2011. A hierarchical spatial frame-work and database for the national river fish habitat condition assessment. Fisheries 36: 436-449.

Wang, L., Brenden, T.O., Cao, Y, and Seelbach, P.W. 2011. Delineation and validation of river network spatial scales for water resources and fisheries management. Environ. Manag. 50: $875-887$.

Warrner, S.S., Fischer, R.U., Holtrop, A.M., Hinz, L.C., and Movak, J.M., 2010. Evaluating the Illinois stream valley segment model as an effective management tool. Environ. Manage. 46: 761-770.

Ward, J.V., and Stanford, J.A. 1983. Serial discontinuity concept of lotic ecosystems. In Dynamics of Lotic Systems Edited by T.D. Fontaine \& S.M. Bartell. Ann Arbor Science, Ann Arbor. pp. 29-42.

Wiens, J.A. 1989. Spatial scaling in ecology. Funct. Ecol. 3: 385-397.

Zorn, T.G., Seelbach, P.W., and Wiley, M.J. 2002. Distributions of stream fishes and their relationship to stream size and hydrology in Michigan's Lower Peninsula. Trans. Amer. Fisheries Soc. 131:70-85.

Zorn, T.G., Seelbach, P.W., and Wiley, M.J. 2011. Relationships between habitat and fish density in Michigan Streams. N. A. J. Fish. Manag. 31: 41-55. 
Figures

462 Figure 1. The relationship between drainage basin size (area) and the heterogeneity of

463 landscape types they contain. A) illustrates the many different landscape types, perhaps surficial

464 geology (coloured polygons), that influence the Saugeen River at its outlet, B) shows a smaller

465 nested subwatershed, which has noticeably fewer landscape types present within, and C)

466 demonstrates that in the context of this scenario a very small headwater catchment can be

467 composed of a single landscape type because its drainage area is smaller than the patch size.

468 Note scale in the top right-hand corner of each panel.

469 Figure 2. The probability of an abrupt change downstream from a confluence is a function of

470 both confluence symmetry ratio (CSR, the ratio of tributary drainage area to main stem drainage

471 area) and the similarity of drainage characteristics in a logistic functional form (Equation 1). The

472 probability of an abrupt change is high (red shade) when two streams merge of a similar size

$473(\mathrm{CSR}>0.8)$ and drainage characteristics are similar (similarity $<10)$. As the similarity of the

474 two drainages decreases (i.e., landscape characteristics), the inflection point of the logistic

475 function shifts to progressively lower CSR values.

476 Figure 3. Area-weighted values of base flow index (BFI, Neff et al. 2005) as a function of

477 drainage area $\left(\mathrm{km}^{2}\right)$. The mean base flow index value for all drainages combined is $46 \%$ and

478 represented by the dashed line.

479 Figure 4. Confluence symmetry ratio vs the similarity of landscape characteristics by drainage

480 size $\left(\right.$ area $\left.\mathrm{km}^{2}\right)$. The absences of data points on the left side of $<10 \mathrm{~km}^{2}$ panel is an artifact of the

481 minimum area $\left(1 \mathrm{~km}^{2}\right)$ required to form a stream in our spatial base data such that the smallest

482 ratio possible is $1 / 10 \mathrm{~km}^{2}$ in the $<10 \mathrm{~km}^{2}$ bin. 
483 Figure 5. Counts for confluences with various combinations of confluence symmetry ratio and 484 similarity of drainage characteristics in southern Ontario. Red shade for low counts and green for 485 high counts. The jagged vertical line separates combinations of CRS and landscape similarity 486 that are significant (right side, probability of significant downstream effects $\geq 0.9$ ) with 487 confluences that are not significant (left side, probability of significant downstream effects $\leq 0.9$ ).

Figure 6. Stream network map showing the probability of change downstream of confluences in 489 the Saugeen River. The potential for change as a logistic function of confluence symmetry ratio 490 and the (dis)similarity of landscape characteristics calculated as a Euclidean distance (see Fig. 2).

491 North Saugeen (A), Rocky Saugeen (B), main channel Saugeen (C), Beatty Saugeen (D), South 492 Saugeen (E), and Teeswater (F) shown with red water lines. Symbology for confluence symmetry ratio is reflected in size of circles at confluences. Colour ramp indicates probability for 494 change in the stream segment downstream of the confluence. Red shade = high probability; 495 green shade = low probability. Figure 7. Expected patterns of change in the Saugeen River and its main tributaries based on the 497 logistic function of confluence symmetry ratio and the (dis)similarity of landscape characteristics 498 calculated as a Euclidean distance (see Fig. 2). North Saugeen (A), Rocky Saugeen (B), main 499 channel Saugeen (C), Beatty Saugeen (D), South Saugeen (E), and Teeswater (F) shown with red 500 water lines.

501 Figure 8. Upstream drainage area $\left(\mathrm{km}^{2}\right)$ in relation to the potential for change downstream of 502 confluences in the Saugeen River. The main stem upstream drainage is used for area. 

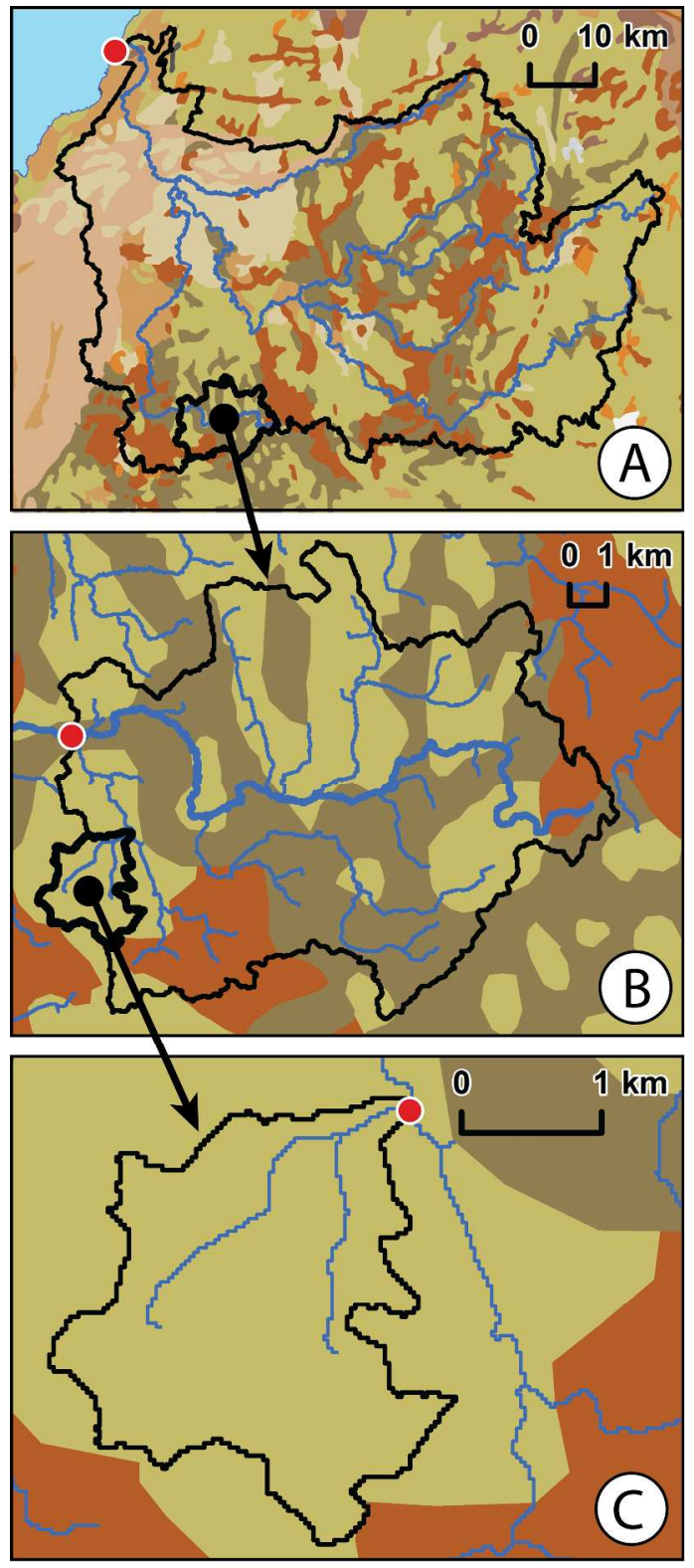

Figure 1. The relationship between drainage basin size (area) and the heterogeneity of landscape types they contain. A) illustrates the many different landscape types, perhaps surficial geology (coloured polygons), that influence the Saugeen River at its outlet, B) shows a smaller nested subwatershed, which has noticeably fewer landscape types present within, and C) demonstrates that in the context of this scenario a very small headwater catchment can be composed of a single landscape type because its drainage area is smaller than the patch size. Note scale in the top right-hand corner of each panel. 


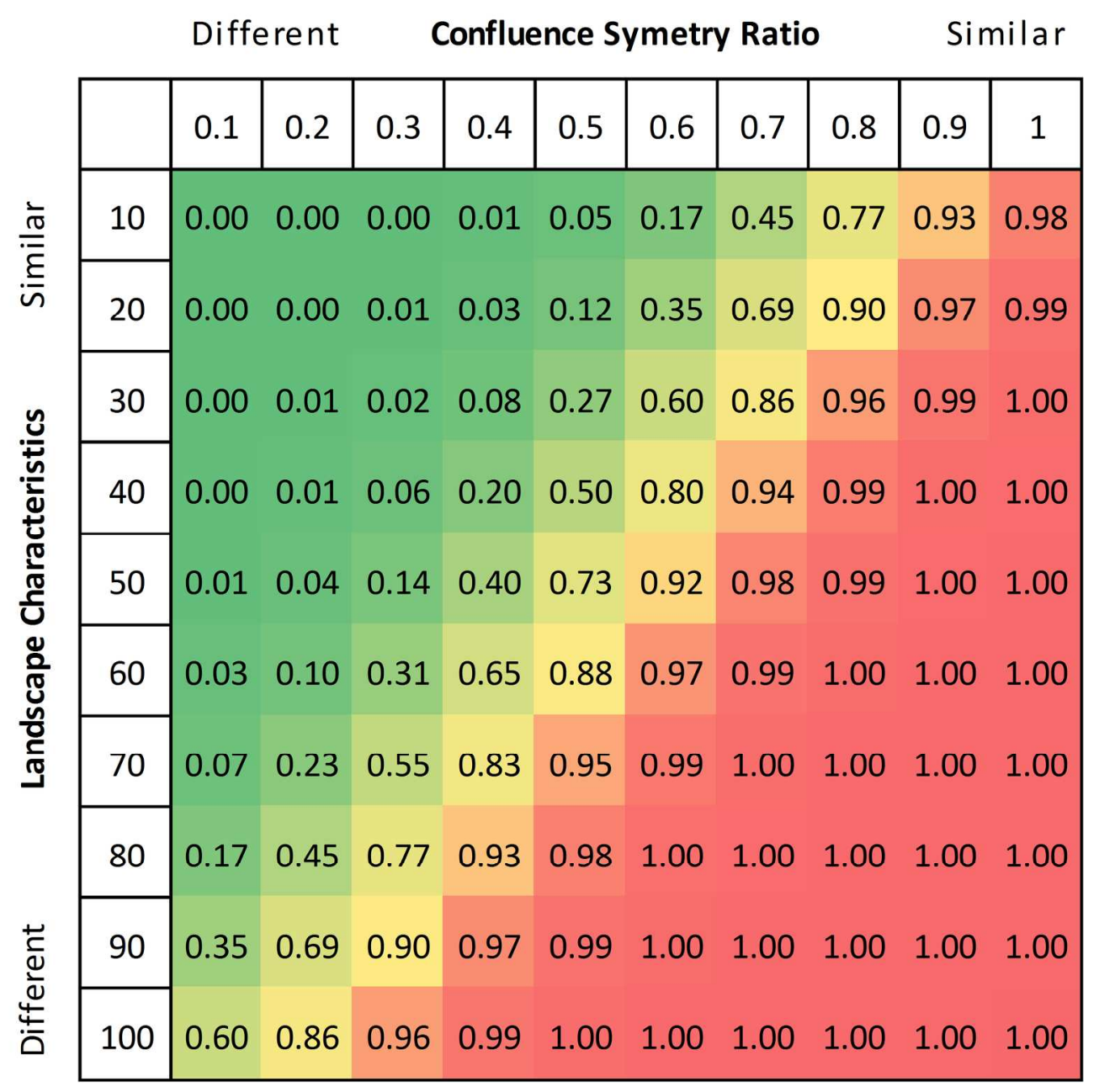

Figure 2. The probability of an abrupt change downstream from a confluence is a function of both confluence symmetry ratio (CSR, the ratio of tributary drainage area to main stem drainage area) and the similarity of drainage characteristics in a logistic functional form (Equation 1). The probability of an abrupt change is high (red shade) when two streams merge of a similar size (CSR >0.8) and drainage characteristics are similar (similarity < 10). As the similarity of the two drainages decreases (i.e., landscape characteristics), the inflection point of the logistic function shifts to progressively lower CSR values. 


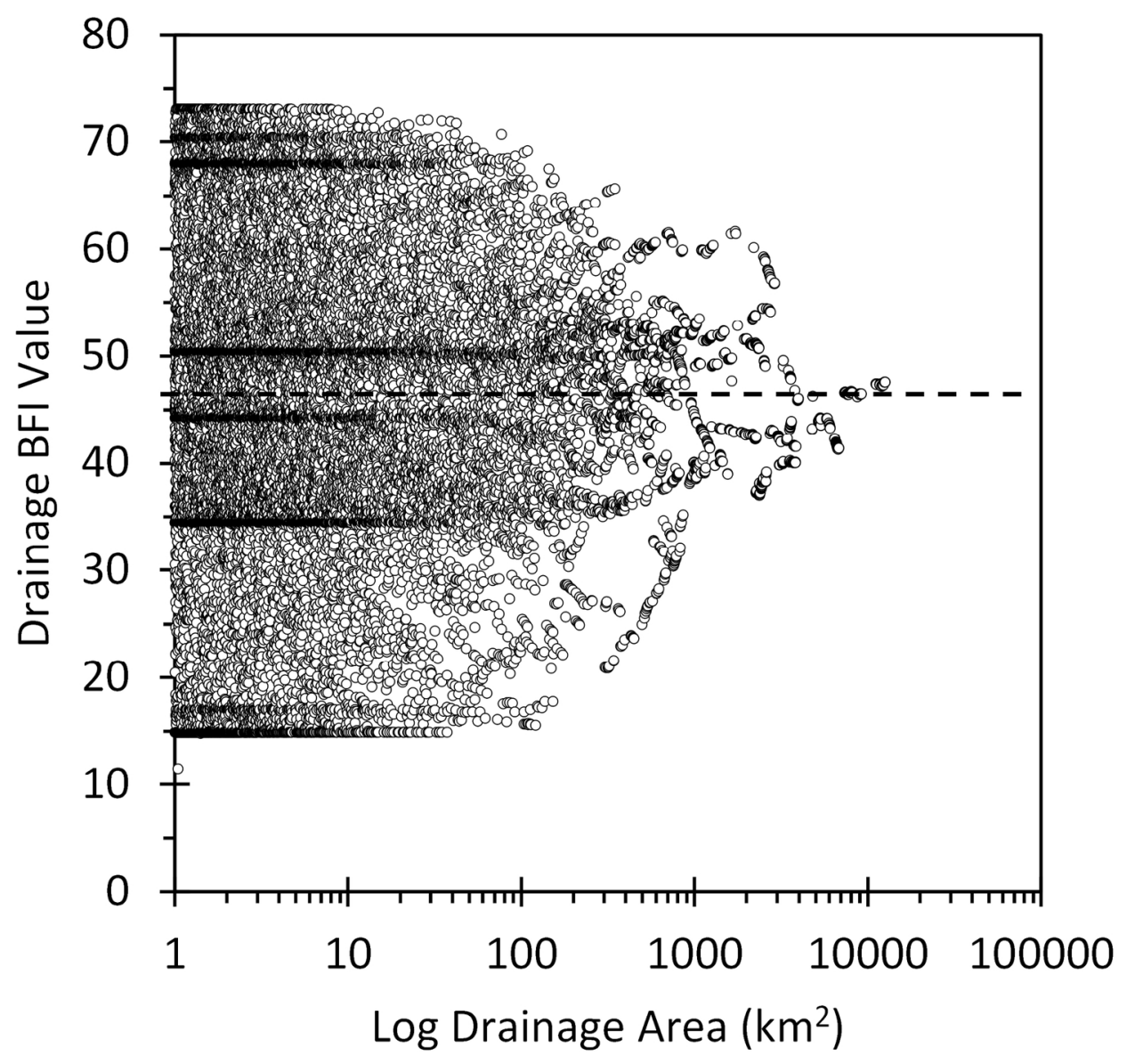

Figure 3. Area-weighted values of base flow index (BFI, Neff et al. 2005) as a function of drainage area $\left(\mathrm{km}^{2}\right)$. The mean base flow index value for all drainages combined is 46 and represented by the dashed line.

$82 \times 80 \mathrm{~mm}(600 \times 600 \mathrm{DPI})$ 

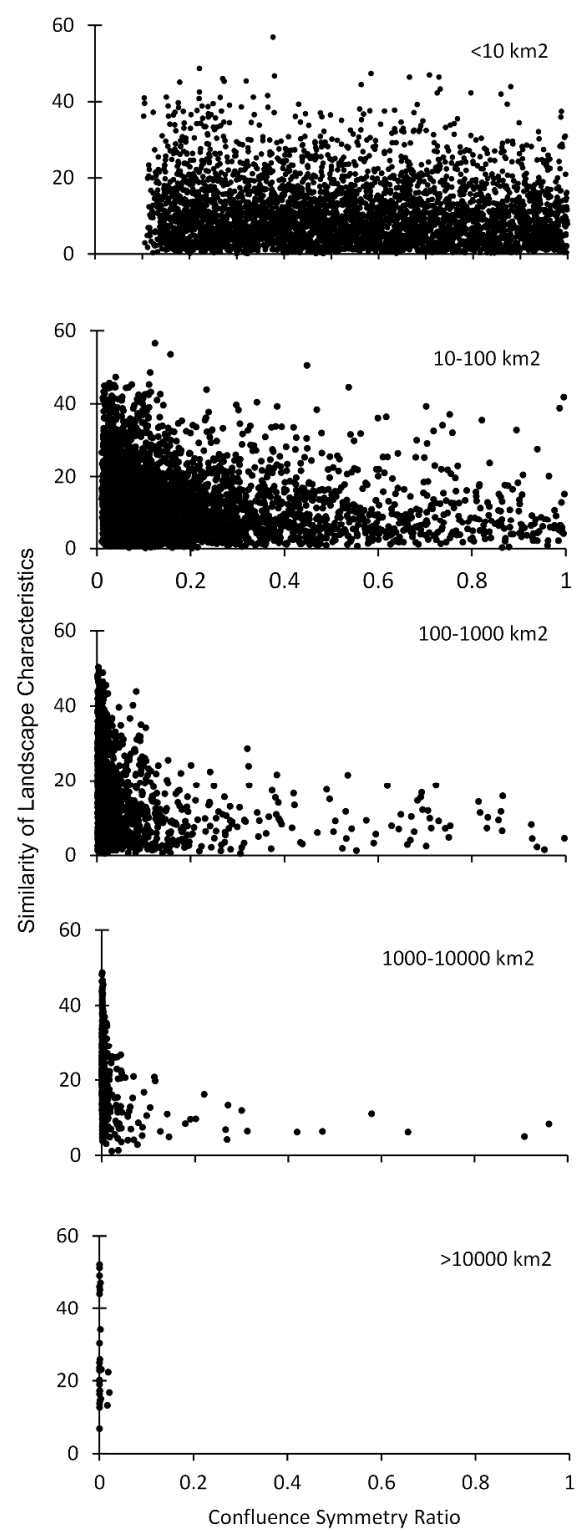

Figure 4. Confluence symmetry ratio vs the similarity of landscape characteristics by drainage size (area $\left.\mathrm{km}^{2}\right)$. The absences of data points on the left side of $<10 \mathrm{~km}^{2}$ panel is an artifact of the minimum area (1 $\mathrm{km}^{2}$ ) required to form a stream in our spatial base data such that the smallest ratio possible is $1 / 10 \mathrm{~km}^{2}$ in the $<10 \mathrm{~km}^{2}$ bin.

$221 \times 579 \mathrm{~mm}(600 \times 600 \mathrm{DPI})$ 


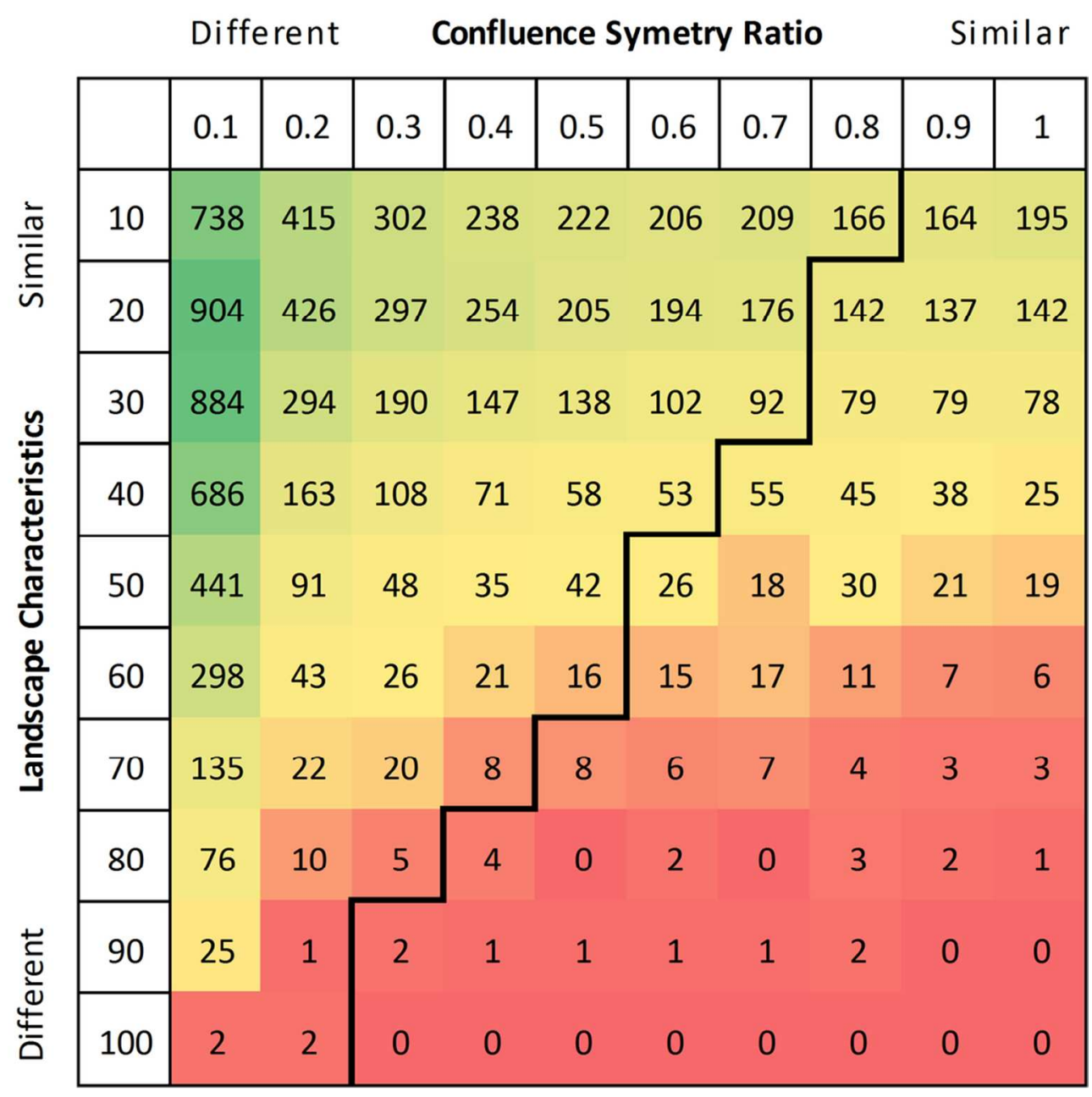

Figure 5. Counts for confluences with various combinations of confluence symmetry ratio and similarity of drainage characteristics in southern Ontario. Red shade for low counts and green for high counts. The jagged vertical line separates combinations of CRS and landscape similarity that are significant (right side, probability of significant downstream effects $\geq 0.9$ ) with confluences that are not significant (left side, probability of significant downstream effects $\leq 0.9$ ).

$95 \times 95 \mathrm{~mm}(300 \times 300 \mathrm{DPI})$ 


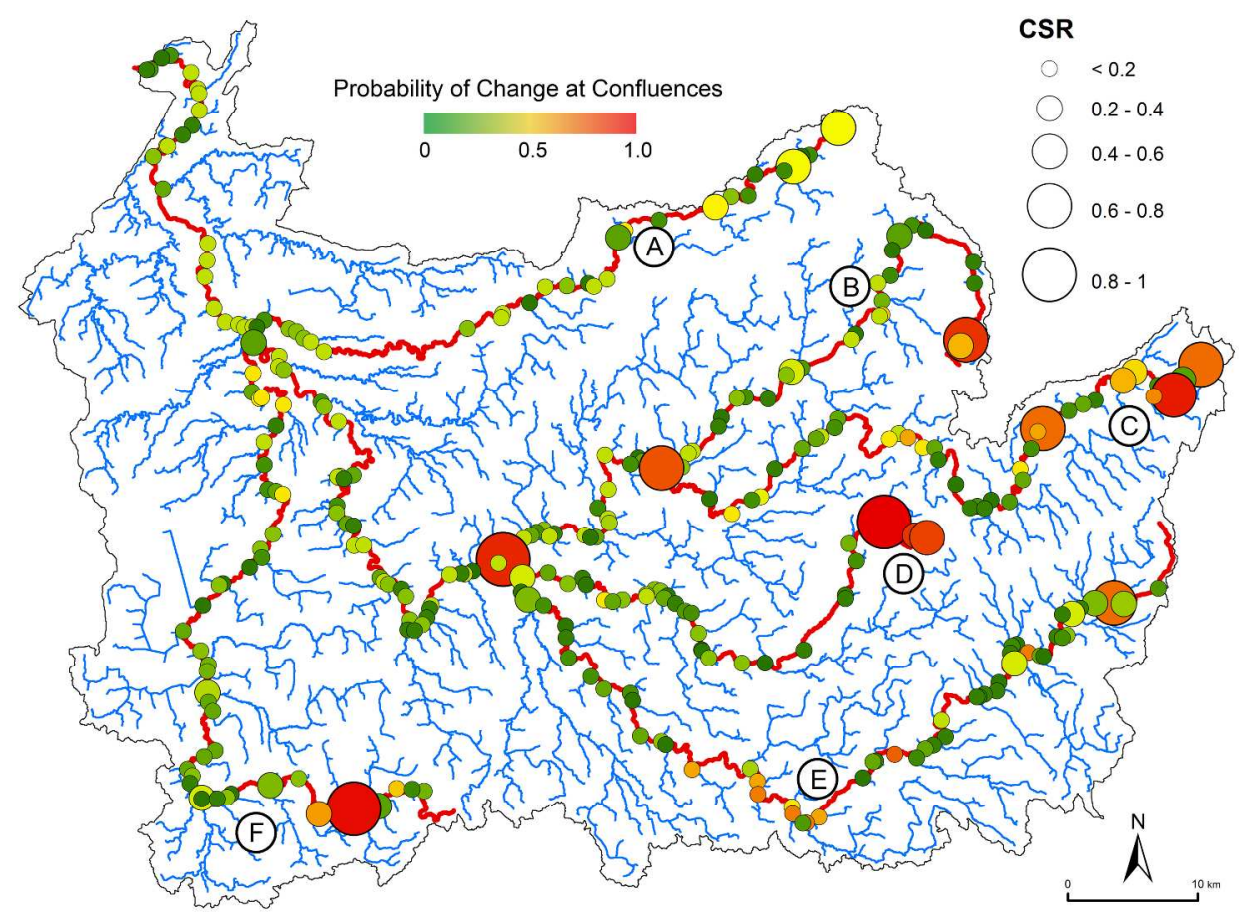

Figure 6. Stream network map showing the probability of change downstream of confluences in the Saugeen River. The potential for change as a logistic function of confluence symmetry ratio and the (dis)similarity of landscape characteristics calculated as a Euclidean distance (see Fig. 2). North Saugeen (A), Rocky Saugeen (B), main channel Saugeen (C), Beatty Saugeen (D), South Saugeen (E), and Teeswater (F) shown with red water lines. Symbology for confluence symmetry ratio is reflected in size of circles at confluences. Colour ramp indicates probability for change in the stream segment downstream of the confluence. Red shade $=$ high probability; green shade = low probability.

$129 \times 96 \mathrm{~mm}(600 \times 600 \mathrm{DPI})$ 

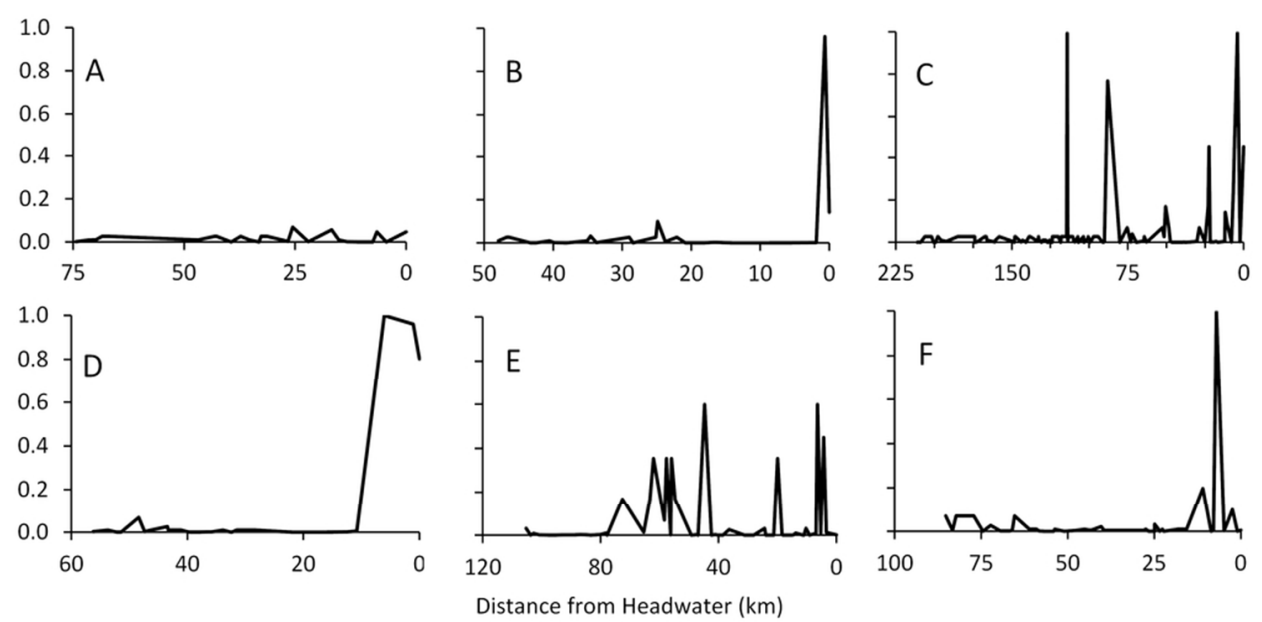

Figure 7. Expected patterns of change in the Saugeen River and its main tributaries based on the logistic function of confluence symmetry ratio and the (dis)similarity of landscape characteristics calculated as a Euclidean distance (see Fig. 2). North Saugeen (A), Rocky Saugeen (B), main channel Saugeen (C), Beatty Saugeen (D), South Saugeen (E), and Teeswater (F) shown with red water lines.

$89 \times 43 \mathrm{~mm}(300 \times 300$ DPI $)$ 


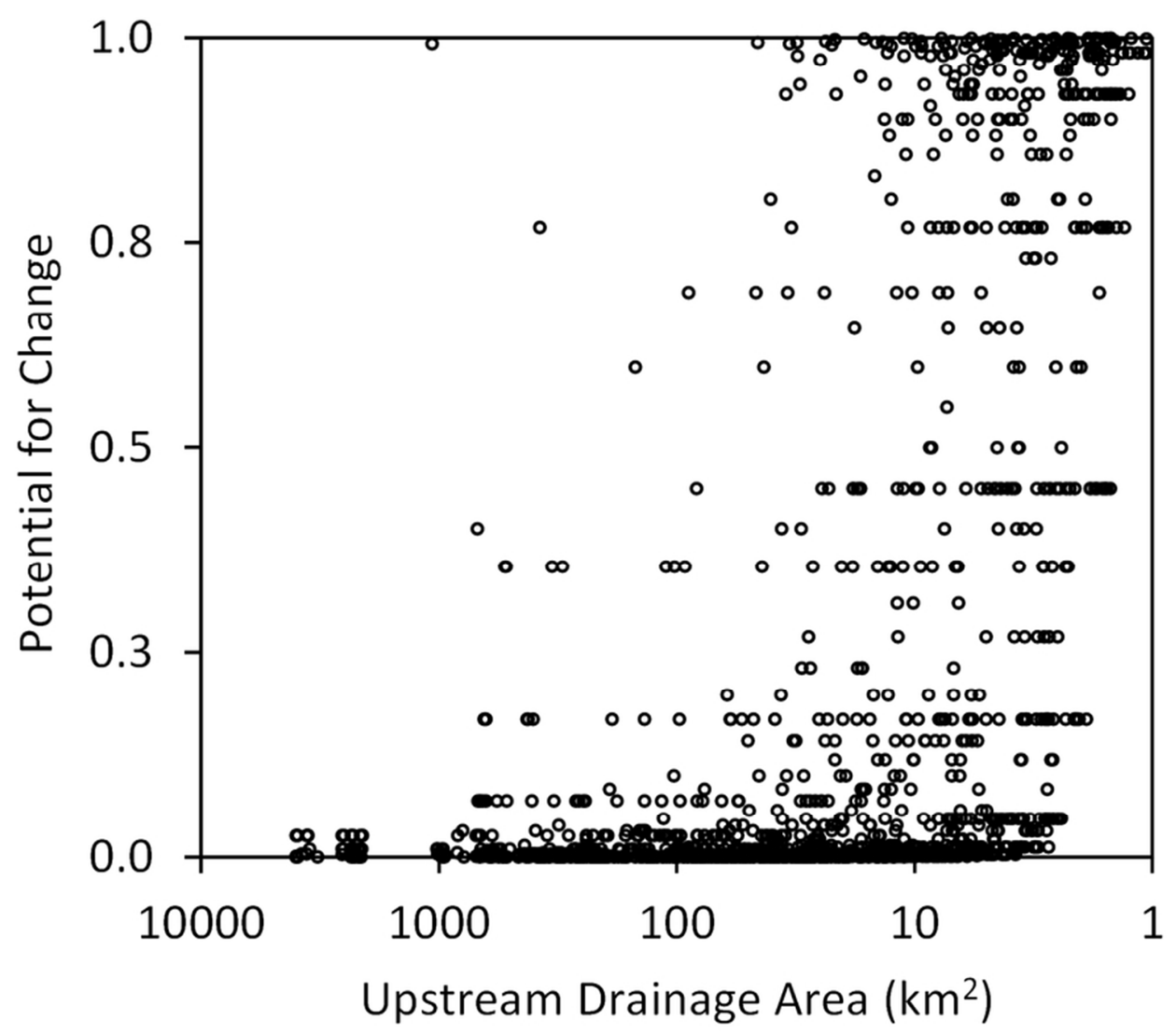

Figure 8. Upstream drainage area $(\mathrm{km} 2)$ in relation to the potential for change downstream of confluences in the Saugeen River. The main stem upstream drainage is used for area.

$78 \times 72 \mathrm{~mm}(300 \times 300$ DPI $)$ 